\title{
HYDROGEOLOGY OF THRUST FAULTS AND CRYSTALLINE THRUST SHEETS: RESULTS OF COMBINED FIELD AND MODELING STUDIES
}

\author{
Craig B. Forster \\ Department of Geology \& Geophysics, University of Utah \\ James P. Evans \\ Department of Geology, Utah State University
}

Abstract. Field, laboratory, and modeling studies of faulted rock yield insight into the hydraulic character of thrust faults. Late-stage faults comprise foliated and subparallel faults, with clay-rich gouge and fracture zones, that yield interpenetrating layers of low-permeability gouge and higher-permeability damage zones. Laboratory testing suggests a permeability contrast of two orders of magnitude between gouge and damage zones. Layers of differing permeability lead to overall permeability anisotropy with maximum permeability within the plane of the fault and minimum permeability perpendicular to the fault plane. Numerical modeling of regional-scale fluid flow and heat transport illustrates the impact of fault zone hydrogeology on fluid flux, fluid pore pressure, and temperature in the vicinity of a crystalline thrust sheet.

\section{Introduction}

Fault zones can form complex conduit-barrier features that may largely determine the regional-scale patterns and rates of mass and heat transfer in the upper crust [Smith et al., in press]. Faults can transmit meteoric water to depths in excess of $10 \mathrm{~km}$ and water flowing within faults can dissolve, transport, and deposit minerals in the fault [Kerrich, 1986]. As a consequence, patterns and rates of groundwater flow in the upper crust must ultimately influence the rheologic properties of rocks in faults and shear zones [Kerrich, 1986].

The dynamic interaction of fault evolution and flow system development is a transient problem of coupled fluid flow, solute transport with chemical reactions, heat transfer, and deformation that is computationally intractable. Previous modeling studies address different subsets of this problem (e.g., Shi and Wang, 1987; Deming et al., 1990; Ge, 1990). We use combined field and modeling studies to assess how high-relief surface topography and the permeability structure of thrust faults might influence fluid fluxes, pressures, and temperatures in an inactive thrust fault and throughout the overlying thrust sheet. Although we model only idealized hydrogeologic regimes, the modeling results help us to understand how faultrelated flow systems are modified during the changes in topography and permeability associated with fault evolution.

Although this paper addresses only the fluid flow systems that may develop once faulting has ceased, the overall aim of our research is to examine the evolution of fluid flow systems during thrusting. We pose three questions: (1) how do fluids reach and leave fault zones in a given structural setting?, (2) how do fluids migrate within, and interact with, fault rocks?, and (3) how do spatial and temporal variations in hydraulic properties of fault zones and protolith influence both local and mappin-scale flow systems and thermal regimes? We use field mapping and laboratory testing to collect the data required to micross these questions across scales ranging from microscopic to megascopic. Numerical modeling results,

Copyright 1991 by the American Geophysical Union.

Paper number 91GL00950

0094-8534/91/91GL-00950\$03.00

obtained for systems that span a wide range of spatial scales, aid in establishing appropriate scales of observation. Although our numerical models cannot provide a unique answer that applies directly to a given field situation, the numerical results do provide insight into this class of groundwater flow system.

\section{Fault Zone Hydrogeology}

Precambrian granites and gneisses found in our field area (northwest Wyoming) were thrusted over adjacent sedimentary rocks along moderately-dipping thrust faults. About $150 \mathrm{~m}$ of exposed fault were examined through large-scale field mapping and detailed sampling both across and along strike. Wellfoliated, indurated gouge and very fine-grained, foliated cataclasite form the core of the thrust fault [Evans, 1990]. The surrounding damage zone comprises faulted and fractured granitic gneiss. Total thickness of catalasite and damage zone ranges from 5 to $20 \mathrm{~m}$. Faults located within the damage zone are subparallel to the main fault; imparting a relatively high permeability within the plane of the fault. Late-stage quartz veins parallel to the faults are evidence for higher permeability during fault evolution [Evans, 1990]. Fracture networks that acted as fluid pathways at different stages in fault evolution are mapped in outcrop structures, polished hand samples, and thin sections.

Finite element modeling of isothermal fluid flow within digitized versions of the 2-dimensional fracture networks (e.g., Figure 1a) provides estimates of the average flux of fluid through the model domain. Each fracture segment is represented as an open conduit with parallel bounding surfaces surrounded by impermeable matrix blocks. First, a uniform hydraulic gradient of $2 \times 10^{-3}$ is oriented parallel to the main fault to estimate the equivalent permeability $\left(\mathrm{k}_{\mathrm{e}}\right)$ along the fault. Next, the gradient is reoriented perpendicular to the fault to

(a)

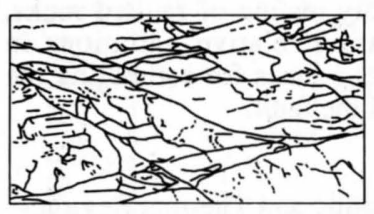

$1 \mathrm{~cm}$

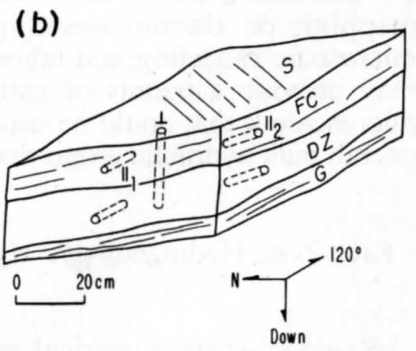

Fig. 1. Fault-related rocks: a) line drawing of a thin section cut parallel to slip direction (S) and perpendicular to the dominant foliation from a damaged zone with transgranular fractures that, in turn, connect zones of intragranular fractures, b) rock sample containing a gouge zone (G), a zone of foliated cataclasite (FC), and a fractured damage zone (DZ). Oriented cores cut both perpendicular $(\perp)$ and parallel ( $\|_{1}$ and $\|_{2}$ ) to the foliation are indicated. 
Table 1. Numerical and experimental estimates of the permeability $\left(\mathrm{m}^{2}\right)$ of fault-related rocks

\begin{tabular}{lcc}
\hline \multicolumn{1}{c}{ Method of Estimating k } & Parallel to Fault $(\mathrm{II})$ & Perpendicular to Fault $(\perp)$ \\
\hline Numerical Estimate - Gouge $\left(\mathrm{k}_{\mathrm{e}}\right.$ for $1 \mu \mathrm{m}$ apertures) & $2 \times 10^{-17}$ & $3 \times 10^{-18}$ \\
Numerical Estimate - Gouge $\left(\mathrm{k}_{\mathrm{e}}\right.$ for $10 \mu \mathrm{m}$ apertures) & $2 \times 10^{-14}$ & $3 \times 10^{-15}$ \\
Lab Tests on Gouge & $1.0 \times 10^{-17}\left(\mathrm{II}_{1}\right), 6.0 \times 10^{-17}\left(\mathrm{II}_{2}\right)$ & $2.0 \times 10^{-17}$ \\
Lab Tests on Damaged Zone & $1.2 \times 10^{-15}$ and $3.0 \times 10^{-15}$ & ${ }^{--}$ \\
Lab Tests on Protolith & $1.4 \times 10^{-16}$ and $2.3 \times 10^{-16}$ \\
\hline
\end{tabular}

estimate $\mathrm{ke}_{\mathrm{e}}$ across the fault. In each case, domain boundaries parallel to the direction of the applied hydraulic gradient are assumed impermeable. Computed values of $\mathrm{ke}_{\mathrm{e}}$ (Table 1) represent the permeability of the equivalent porous medium that, when subjected to the same hydraulic gradient, yields a volumetric flow rate matching that computed for the corresponding fractured medium. Two cases are simulated; each with uniform, but different, fracture apertures $(1 \mu \mathrm{m}$ and $10 \mu \mathrm{m})$. Modeling results suggest that the geometry of the fracture network alone (Figure 1a) can impart an anisotropic character to the permeability structure within the fault; computed values of $\mathrm{k}_{\mathrm{e}}$ parallel to the fault are about 6 times $\mathrm{ke}$ perpendicular to the fault (Table 1).

Steady-state permeability tests of $2.5 \mathrm{~cm}$ diameter cores from gouge, damaged zone, and protolith (Figure $1 \mathrm{~b}$ ) yield $\mathrm{k}$ values ranging from $1 \times 10^{-17}$ to $3 \times 10^{-15} \mathrm{~m}^{2}$ (Table 1). Although permeabilities are larger than expected during fault development, the relative variation in permeability from protolith (intermediate k), through damage zone (high k), to gouge zone (low k) is likely representative of conditions within many faults. Alternating zones of high and low $\mathrm{k}$ within a fault impart an effective anisotropy to the overall permeability structure of the fault; maximum permeability parallels the fault plane and minimum permeability is perpendicular to the fault.

Values of fault gouge $\mathrm{k}$ are within the range reported for other laboratory tests (10-21 to $\left.10^{-12} \mathrm{~m}^{2}\right)$ [see Smith et al., in press]. Values of damage and gouge zone permeablity are also within the range $\left(10^{-17}\right.$ to $\left.10^{-11} \mathrm{~m}^{2}\right)$ obtained from in situ testing of $\mathrm{k}$ within a thrust fault in crystalline rocks [Davison and Kozak, 1988].

Laboratory-determined and numerically-derived estimates of gouge permeability parallel to the fault show similar values of $k$ (about $10-17 \mathrm{~m}^{2}$ ) if a fracture aperture of $1 \mu \mathrm{m}$ is assumed (Table 1). If a fracture aperture of $10 \mu \mathrm{m}$ is assumed, the numerical estimate of $k_{e}$ exceeds the laboratory-determined value of $\mathrm{k}$ by at least two orders of magnitude (Table 1). Thus, fracture apertures in the sample tested may be closer to 1 $\mu \mathrm{m}$ than $10 \mu \mathrm{m}$. The apparent similarity between numerical estimates of $\mathrm{k}_{\mathrm{e}}$ and the laboratory $\mathrm{k}$ tests suggests that detailed mapping of fractures within the fault, combined with microscale modeling and laboratory testing of faulted rocks, may provide a means of estimating relative variations in microscale $\mathrm{k}$ that could be used as a basis for estimating the overall bulk hydraulic properties of the fault.

\section{Fault Zone Hydrogeology: Hydraulic and Thermal Regimes}

Regional-scale numerical modeling studies illustrate how fault zone hydrogeology might influence fluid flux, fluid pore pressure, and temperature in the vicinity of a thrust fault. The idealized model domain and the distribution of permeability and porosity in our reference case (Figure 2a) represents one of a series of range-basin topographic features typical of the deformed foreland of Wyoming. Vertical boundaries mark the approximate locations of the sub-vertical groundwater divides expected between each adjacent thrust sheet. Although we consider only the present-day case of an inactive fault the modeling results provide insight into the underlying hydraulic regime that would exist where steep topographic relief is maintained throughout fault evolution.

A shallow water table coincides with the upper boundary and vertical boundaries are both insulated and impermeable. A uniform regional heat flux of $60 \mathrm{~mW} \mathrm{~m}^{-2}$ is applied along the basal, impermeable boundary. Temperatures on the upper boundary are specified as a function of elevation, except at the thrust fault outcrop where a free-temperature boundary condition is assigned to allow a thermal spring to develop.

Values of bulk k (Figure 2a) are controlled by fracturing within the rock mass. At the regional scale each unit is treated as an equivalent, isotropic porous medium. The crystalline thrust sheet is assigned a value of $\mathrm{k}$ typical of relatively

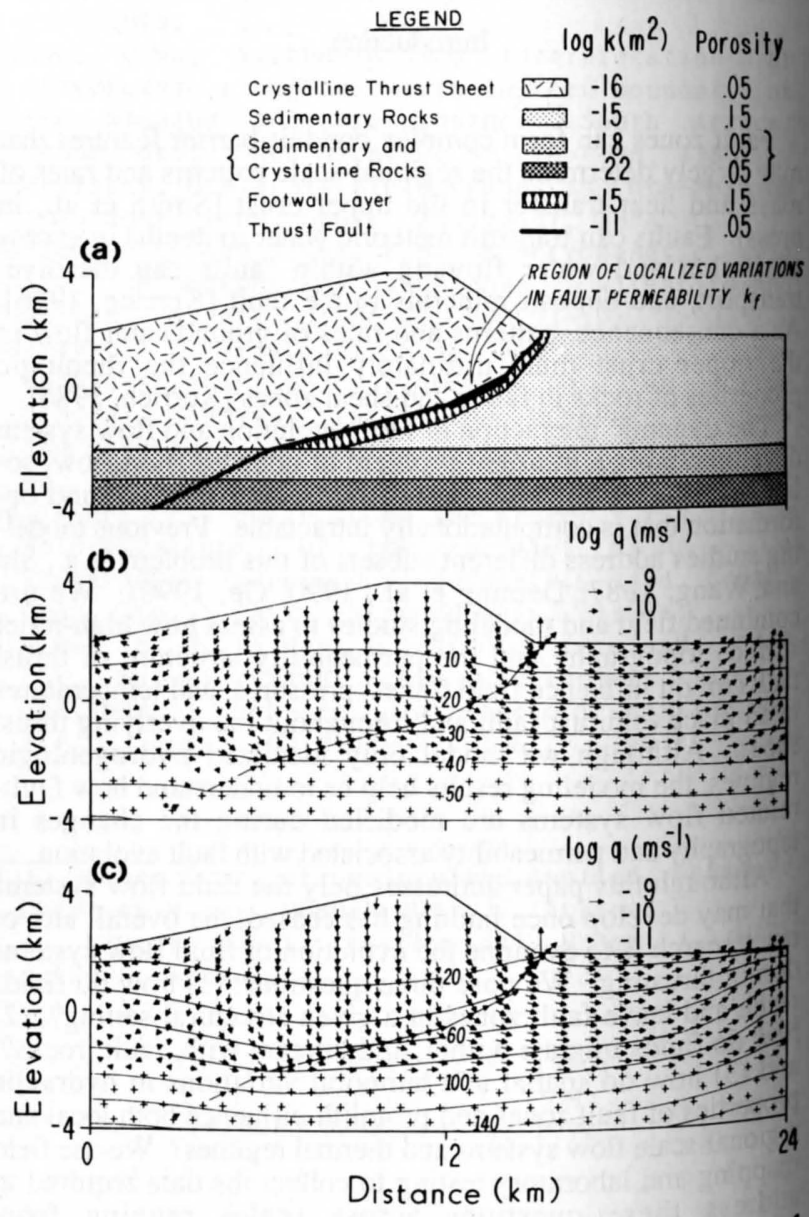

Fig. 2. Regional-scale modeling of the reference case (Run 1 in Table 2): a) model domain and permeability structure, b) fluid flux vectors and contours of fluid pore pressure (MPa), and c) fluid flux vectors and contours of temperature $\left({ }^{\circ} \mathrm{C}\right)$. Plus signs (+) shown in (b) and (c) indicate regions where fluid flux is less than $10^{-12} \mathrm{~m} \mathrm{~s}^{-1}$. 
unfractured crystalline rock $\left(10-16 \mathrm{~m}^{2}\right)$. The higher-k sedimentary package is assigned a value representative of many carbonate and clastic rocks $\left(10^{-15} \mathrm{~m}^{2}\right)$. Two basal layers are incorporated in the model to represent a general decline, with increasing depth, in permeability of both crystalline and sedimentary rocks. Thermal conductivity and specific heat of fluid and rock are assumed constant. Porosity is varied from 0.05 to 0.15 (Figure 2a). Fluid density and viscosity are of a function of temperature and pressure.

The thrust fault is represented as a discrete feature with permeability $\mathrm{kf}$ and width $\mathrm{b}$. Both $\mathrm{kf}$ and $\mathrm{b}$ may be varied independently along the fault. A value of $10^{-11} \mathrm{~m}^{2}$ is selected for $\mathrm{kf}$ in our reference case to demonstrate the maximum impact a permeable thrust fault might have on the regional-scale fluid flow and thermal regimes. This is the upper limit of fault permeability measured in situ within a thrust fault [Davison and Kozak, 1988]. Fault width (b) is $1 \mathrm{~m}$.

Coupled equations of steady-state fluid flow and heat transfer are solved using the finite element method. The fault is represented by superimposing a series of line elements on a field of triangular elements. Forster and Smith [1988] outline the complete boundary value problem and modeling approach.

\section{Regional-Scale Modeling Results}

Groundwater recharges at high elevations and discharges both at the fault outcrop and at low elevations near each end of the model domain (Figures $2 \mathrm{~b}$ and $2 \mathrm{c}$ ). In unfaulted terrain groundwater would be transmitted more pervasively through shallower regions of the model domain. Focusing of fluid flow within the fault increases the potential for localized fluidassisted chemical reactions and promotes temporal and spatial variations in fault rheology and permeability.

Changes in fluid flux along the fault are closely related to variations in permeability of the surrounding protolith. Although fault permeability is high at the base of the model domain, the lack of recharge from surrounding lowpermeability basal units yields limited fluid flow deep within the fault. Maximum values of fluid flux are found at shallow depths where the fault is adjacent to the higher-permeability crystalline thrust sheet and the full impact of topographicallyinduced hydraulic gradients is transmitted to the fault.

A three-order of magnitude increase in fluid flux is computed as fluid flows from the thrust sheet to the underlying fault (Figures $2 \mathrm{~b}$ and $2 \mathrm{c}$ ). This result suggests that water-rock ratios derived for the fault, using estimates of the volume of water transmitted through a unit volume of fault rock, could greatly exceed those derived for the overlying thrust sheet. Thus, caution should be exercised when estimating fluid flux and fluid transit times within an overlying thrust sheet [e.g., Losh, 1989]. Computed transit times are $10^{5}$ years for meteoric water recharging at the ridgetop to reach the fault and an additional 300 years for water to discharge at the ground surface after migrating through about $3.7 \mathrm{~km}$ of the fault.

The topographically-driven flow system contributes to nonhydrostatic vertical pressure gradients, therefore directions and rates of fluid flow cannot be inferred solely on the basis of a incw point estimates of fluid pressure obtained from fluid computen studies or in situ measurements. For example, computed directions of fluid flux (Figure 2b) indicate pore prester can move either down or up local gradients in the pressure. Fluid pressures throughout the central part of relative domain are underpressured by as much as $12 \mathrm{MPa}$ condive to those that might be computed assuming hydrostatic Underpens within the thermal regime of Figure $2 c$. pressure sheet whilients develop within the low-permeability thrust permeable pressure gradients in the underlying morepeable sedimentary package are approximately hydrostatic.
Pressure perturbations that develop during fault evolution would be superimposed on the topographically-induced pressure regime. For example, pore volume reduction and thermal pressurization within an active fault could cause temporary lithostatic pore fluid pressures within 1 or 2 meters of the fault [Mase and Smith, 1987]. In addition, compression of the sedimentary package during a thrust event could cause regional-scale perturbations of the groundwater flow system [Ge, 1990; Deming et al., 1990]. Additional studies are required to assess the relative importance of topographicallyand tectonically-driven flow near a thrust fault.

\section{Fault Zone Scale Parametric Study}

A series of simulations (Table 2) illustrate the relative impact of fault and protolith permeability on the temperature (T), pore fluid pressure (P), and fluid flux (q) conditions encountered by fluid moving through the fault shown in Figure 2a. Variations in $\mathrm{q}$ are plotted as a function of distance along the fault (Figure 3 ) with 0.0 located where the fault intersects the basal boundary (Figure 2 ). The permeability structure shown in Figure $2 \mathrm{a}$ is the reference case. Computed values of $\mathrm{T}, \mathrm{P}$, and q vary along the fault in a nonlinear fashion that cannot be obtained using simple analytical solutions.

\section{Table 2. Summary of Modeling Runs}

\begin{tabular}{cll}
\hline RUN & \multicolumn{1}{c}{ SCENARIO } & CHARACTERISTICS \\
\hline 1 & Reference case (RC) & k structure of Figure 3a \\
2 & Unfaulted case & RC minus fault \\
3 & Anisotropic fault & RC k footwall layer $10-18 \mathrm{~m}^{2}$ \\
4 & $\mathrm{k}_{\mathrm{f}}$ on 2 km of fault & $\mathrm{RC}, \mathrm{k}_{\mathrm{f}}$ of $10-12 \mathrm{~m}^{2}$ \\
5 & Reduced thrust sheet $\mathrm{k}$ & $\mathrm{RC}, \mathrm{k}$ thrust sheet $10-17 \mathrm{~m}^{2}$ \\
\hline
\end{tabular}

Modeling results indicate that the fault has a pervasive impact on temperature and pressure distributions both within the fault and throughout the modeling domain. In the absence of a permeable fault (Run 2), fluid pressures near the base of the domain rise as high as $3 \mathrm{MPa}$ above those obtained at the corresponding location in the reference case (Run 1). The permeable fault transmits topographically-derived hydraulic

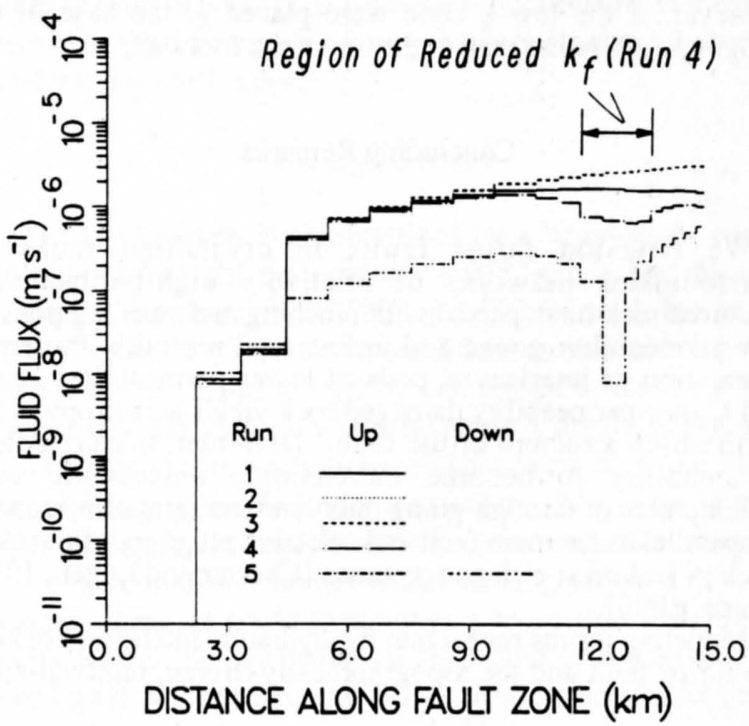

Fig. 3. Fluid flux computed along the thrust fault shown in Figure $2 \mathrm{a}$ for a series of runs summarized in Table 2. Except where indicated, fluid flow is generally upward along the fault. 
gradients deep into the flow system and causes regional variations in fluid pore pressures that ultimately depend upon the overall hydraulic character of the fault. The fault exerts a significant impact on temperatures computed within the model domain; temperatures along the upper $5 \mathrm{~km}$ of the fault are elevated by up to $10^{\circ} \mathrm{C}$ above those of the unfaulted case.

The permeability of the crystalline thrust sheet overlying the fault controls the amount of groundwater entering or exiting the fault and the rate of fluid flux within the fault. Reduced groundwater recharge to the fault allows local, topographicallyinduced hydraulic gradients to cause a reversal in fluid flow, from upflow to downflow, at shallow depths in the thrust fault (Run 5 in Figure 3). Reducing the thrust sheet $\mathrm{k}$ from $10^{-16}$ to $10-17 \mathrm{~m}^{2}$ reduces $\mathrm{q}$ in the upper $10.5 \mathrm{~km}$ of the fault by at least one order of magnitude (Figure 3). The sensitivity of fluid fluxes within the fault to the permeability of the thrust sheet indicates that the hydraulic character of the fault cannot be divorced from the surrounding regional groundwater flow system. Reasonable estimates of bulk permeability of the thrust sheet must be made before the magnitude and variability of $\mathrm{q}$ within the fault can be estimated.

Earlier we noted that: 1) a fault can exhibit strong spatial variations in permeability, and 2) that faults developed in crystalline rock may exhibit anisotropic permeability. Reducing the permeability of the fault (kf) from $10^{-11}$ to $10^{-12}$ $\mathrm{m}^{2}$ along the $2 \mathrm{~km}$ fault segment (Figure $2 \mathrm{a}$ ) leads to reduced $\mathrm{q}$ within and adjacent to the region of lower $\mathrm{k}_{\mathrm{f}}$. Little change in $\mathrm{T}$ and $\mathrm{P}$ along the fault is computed because the overall distribution of $\mathrm{P}, \mathrm{T}$, and $\mathrm{q}$ within the regional-scale model domain is little affected by the localized variation in $\mathrm{kf}_{\mathrm{f}}$.

The effective anisotropy associated with layering of gouge and damage zone is simulated by reducing the permeability of a segment of the footwall (footwall layer shown in Figure 2a) from $10^{-15}$ to $10^{-18} \mathrm{~m}^{2}$. This relatively thick gouge zone lies immediately adjacent to the overlying, more-permeable damage zone $\left(\mathrm{k}=10-11 \mathrm{~m}^{2}\right)$. Although a significant increase in fluid flux is indicated along the upper more permeable section of the fault, fluid pressure along the fault is little affected by the change in permeability structure. Computed temperatures in the upper $3 \mathrm{~km}$ of the fault are elevated by up to $5^{\circ} \mathrm{C}$ above those of the reference case. At first glance, these results suggest that it may be more important to determine the bulk permeability of the thrust sheet rather than expend significant effort assessing the magnitude of anisotropy in fault $\mathrm{k}$. Fluid migration into the fault would be significantly reduced, however, if the low $\mathrm{k}$ zone were placed at the base of the hanging wall, rather than at the top of the footwall.

\section{Concluding Remarks}

We envision thrust faults in crystalline rocks as anastomosing networks of relatively high-permeability fractured rock interspersed with pinching and swelling pods of low permeability gouge and unfractured protolith. Preferred orientation of interleaved pods of lower-permeability gouge and higher-permeability damaged rock yields anisotropy in the permeablity structure of the fault. Deformation causes fault permeability to become increasingly anisotropic with development of through-going inter- and intragranular fractures subparallel to the main fault and selective plugging of fractures in clay- and mica-rich gouge zones [Chester and Logan, 1986; Evans, 1990].

Modeling results reveal that the hydraulic interaction of both the thrust fault and the topographically-driven, regional-scale groundwater flow system must be considered. Rates of fluid flow within an inactive thrust fault are strongly influenced by the topography and permeability of the overlying thrust sheet Although the detailed hydraulic character of the fault can influence fluid transit times within the fault and adjacent protolith, local variations in fault permeability have little impact on the regional-scale distribution of temperature and pore pressure. On the other hand, the bulk permeability of the fault can influence regional-scale fluid flow and thermal regimes.

Acknowledgements. Funding provided by National Science Foundation grant \#EAR-9005087, Utah State University research grants, and the University of Utah. Two anonymous reviews improved the manuscript.

\section{References}

Chester, F. M., and Logan, J. M., Implications for mechanical properties of brittle faults from observations of the Punchbowl fault zone, Calif., Pageoph., 124, 80-106, 1986.

Davison, C. C., and Kozak, E. T., Hydrogeological characteristics of major fracture zones in a large granite batholith of the Canadian Shield, Proc. 4th Can./Am. Conf. Hydrogeol, 52-60, 1988.

Deming, D., Nunn, J.A., and Evans, D.G., Thermal effects of compaction-driven groundwater flow from overthrust belts, J. Geophys. Res., 95 , 6669-6683, 1990.

Evans, J. P.,Textures, deformation mechanisms and the role of fluids in cataclastically deformed granitic rocks, in Deformation Mechanisms, Rheology, and Tectonics, edited by R. J. Knipe and E. Rutter, Geol. Soc. Lond. Sp. Pub. 54, 29-39, 1990.

Forster, C.B., and Smith, L., Groundwater flow systems in mountainous terrain 1 . Numerical modeling technique, Water Resour. Res., 24, 999-1010, 1988.

$\mathrm{Ge}, \mathrm{S}$., On the mechanics of tectonically-driven fluid flow in foreland basins, Ph. D. Diss., Johns Hopkins Univ., 215 p., 1990.

Kerrich, R., Fluid infiltration into fault zones: Chemical, isotopic, and mechanical effects, Pageoph., 124, 225-268, 1986.

Losh, S., Fluid-rock interaction in an evolving ductile shear zone and across the brittle-ductile transition, central Pyrenees, France, Am. J. Sci., 289, 600-648, 1989.

Mase, C. W., and Smith, L., Effects of frictional heating on the thermal, hydrologic, and mechanical response of a fault, J.Geophys. Res., 92, 6249-6272, 1987.

Shi, Y., and Wang, C-Y, Two-dimensional modeling of the PT-t paths of regional metamorphism in simple overthrust terrains, Geology, 15, 1048-1051, 1987.

Smith, L., Forster, C. B., and Evans, J. P., Interactions of fault zones, fluid flow and heat transfer at the basin scale, in Hydrogeology of Low Permeability Environments, edited by S.P. Neuman and I. Neretnieks, Int.. Assoc. Hydrogeol., Hydrogeology Selected Papers, 2 , in press.

C. B. Forster, Department of Geology and Geophysics, University of Utah, Salt Lake City, UT, 84112-1183

J. P. Evans, Department of Geology, Utah State University, Logan, UT 84322-4505

(Received January 10, 1991; revised March 7, 1991; accepted March 12, 1991.) 